\title{
Erratum to: Comparison of established and novel purity tests for the quality control of heparin by means of a set of 177 heparin samples
}

\author{
Susanne Alban • Susanne Lühn • Simone Schiemann • Tanja Beyer • Jochen Norwig • \\ Claudia Schilling • Oliver Rädler • Bernhard Wolf • Magnus Matz • Knut Baumann • \\ Ulrike Holzgrabe
}

Received: 8 October 2010 /Accepted: 8 October 2010 /Published online: 30 October 2010

(C) Springer-Verlag 2010

\section{Erratum to: Anal Bioanal Chem \\ DOI 10.1007/s00216-010-4169-7}

Regrettably, there was a mistake in the concentration of heparinase I. The correct concentration of heparinase I should $\mathrm{read} 2.5 \mathrm{mIU} / \mathrm{ml}$.

The online version of the original article can be found at http://dx.doi. org/10.1007/s00216-010-4169-7.

S. Alban $\cdot$ S. Lühn $\cdot$ S. Schiemann

Pharmaceutical Institute, Christian-Albrechts-University,

Gutenbergstr. 76,

24118 Kiel, Germany

T. Beyer $\cdot$ U. Holzgrabe $(\bowtie)$

Institute of Pharmacy and Food Chemistry,

University of Wuerzburg,

Am Hubland,

97074 Wuerzburg, Germany

e-mail: holzgrab@pharmazie.uni-wuerzburg.de

\section{J. Norwig}

Federal Institute for Drugs and Medical Device,

Kurt-Georg-Kiesinger-Allee 3,

53175 Bonn, Germany

C. Schilling $\cdot$ O. Rädler $\cdot$ B. Wolf

Ratiopharm Group,

Graf-Arco-Str. 3,

89079 Ulm, Germany

M. Matz $\cdot$ K. Baumann

Institute of Pharmaceutical Chemistry,

University of Technology Braunschweig,

Beethovenstrasse 55,

38106 Braunschweig, Germany 